\title{
Avaliação quantitativa e qualitativa da fitomassa de leguminosas para uso como cobertura de solo ${ }^{1}$
}

\author{
Quantitative and qualitative evaluation of legumes as soil cover
}

\author{
João Tavares Nascimento ${ }^{2}$ Ivandro de França da Silva ${ }^{3}$
}

\begin{abstract}
Para uso como adubo verde em um experimento em RESUMO Alagoinha-PB, avaliaram-se doze espécies de leguminosas: crotalária (Crotalaria juncea L), guandu (Cajanus cajan L), guandu anão (Cajanus cajan (L) Millsp), calopogônio (Calopogonium mucunoides L), feijão-de-porco (Canavalia ensiformis L), lab-lab (Dolichos lab lab L), kudzu tropical (Pueraria phaseoloides L), siratro (Macroptilium atropurpureum L), leucena (Leucaena leucocephala L), cunhã (Clitoria ternatea L), mucuna preta (Styzolobium aterrimum L), e mucuna cinza (Styzolobium cinereum Piper e Tracy), no DBC com 12 tratamentos, em parcelas de $20 \mathrm{~m}^{2}$, com três repetições. Constataram-se as maiores produções de fitomassa para leucena, guandu, mucuna preta, kudzu tropical, feijão-de-porco e cunhã, enquanto que para a crotalária, a menor produção. A fitomassa do kudzu tropical mostrou-se com melhor qualidade para a incorporação.
\end{abstract}

Palavras-chave: leguminosas, fitomassa, manejo e conservação do solo.

\section{ABSTRACT}

Twelve species of tropical legumes (Crotalaria juncea L, Cajanus cajan L, Cajanus cajan (L) Millsp, Calopogonium mucunoides L, Canavalia ensiformis L, Dolichos lab lab L, Pueraria phaseoloides L, Macroptilium atropurpureum L, Leucaena leucocephala $\mathrm{L}$, Clitoria ternatea L, Styzolobium aterrimum L, Styzolobium cinereum Piper and Tracy) was evaluated for use as green manure or cover crops in an experiment in Alagoinha-PB, Brazil. The used experimental design was a ramdomized complete block design, with 12 treatments in plots of $20 \mathrm{~m}^{2}$, with three repetitions. The largest biomass quantities were produced for Leucaena leucocephala, Cajanus cajan, Styzolobium aterrimum, Pueraria phaseoloides, Canavalia ensiformis and Clitoria ternatea, while Crotalaria juncea, produced the smallest biomass. The biomass of Pueraria phaseoloides, was shown with better quality for the incorporation.
Key words: legumes, mulch, soil management and conservation.

O Nordeste do Brasil caracteriza-se por longos períodos sem precipitação pluviométrica. Nesse contexto, uma cobertura do solo eficiente reduz a perda de água e mantem a temperatura do solo em níveis favoráveis às culturas (BRAGAGNOLO \& MIELNICZUK, 1990). Espécies leguminosas, por exemplo, são eficientes na recuperação de áreas degradadas, na reciclagem de nutrientes e como cobertura de solo (RIBEIRO, 1999). Segundo KIEHL (1985), na formação da cobertura, deve-se considerar além do teor de nitrogênio, o de fibra e a composição da fitomassa. Nesse sentido, o teor fibra em detergente ácido (FDA) dos resíduos, é importante, pois constitui a porção menos digerível da parede celular pelos microorganismos, sendo na sua quase totalidade de celulose e lignina (SILVA, 1990). Assim sendo, este trabalho objetivou caracterizar, nas condições edafoclimáticas locais, as leguminosas mais eficientes e adaptadas para o uso como cobertura do solo, ou, em rotação de culturas na região.

O ensaio foi conduzido por três anos no município de Alagoinha-PB, em um Luvissolo degradado, a partir de abril de 1997 com o plantio de doze espécies de leguminosas: guandu (Cajanus cajan L), guandu anão (Cajanus cajan L. Millsp), lab-lab (Dolichos lab-lab L), mucuna preta (Styzolobium aterrimum L), cunhã (Clitoria ternatea L), calopogônio (Calopogonium mucunoides L), mucuna cinza (Styzolobium

${ }^{1}$ Extraído da Dissertação de Mestrado em Produção Vegetal do primeiro autor, Centro de Ciências Agrárias (CCA), Universidade Federal da Paraíba (UFPB).

${ }^{2}$ Doutorando em Agronomia, Depto de Fitotecnia, CCA, UFPB A1. Pe. Rolim, 124, 68743-580, Castanhal, PA. E-mail: jnascimenton@bol.com.br. Autor para correspondência.

${ }^{3}$ Professor Doutor, Departamento de Solos e Engenharia Rural, CCA, UFPB, CP 02, 58397-000. Areia. PB 
cinereum Piper e Tracy), siratro (Macroptilium atropurpureum L), crotalária (Crotalaria juncea $\mathrm{L}$ ), feijão-de-porco (Canavalia ensiformis L), kudzu tropical (Pueraria phaseoloides L) e leucena (Leucaena leucocephala L); em parcelas de $20 \mathrm{~m}^{2} \mathrm{e}$ espaçamento de $0,5 \mathrm{~m} \times 0,25 \mathrm{~m}$, no $\mathrm{DBC}$, com doze tratamentos e três repetições. Após a análise de variância, as médias foram contrastadas pelo teste Tukey em nível de $5 \%$. A cada ano, houve renovação da cobertura vegetal das parcelas. Para o manejo da área experimental, não foi usado adubo mineral e nem corretivo, apenas a incorporação do material vegetal do ciclo anterior. Em outubro de 1999, foram coletadas amostras de fitomassa em três locais aleatórios com o uso de um quadrado de madeira medindo $(50 \times 50 \mathrm{~cm})$. As amostras foram secadas em estufa a $65^{\circ} \mathrm{C}$ para estimativa da fitomassa (MS t $\mathrm{ha}^{-1}$ ) e trituradas para a avaliação dos teores de cinza (AOAC., 1984), matéria orgânica (SILVA, 1990), nitrogênio total (AOAC., 1984), proteína bruta (SILVA, 1990), fibra em detergente neutro (FDN) e ácido (FDA) pelo método de VAN SOEST (1967).

Nos resultados de produção de fitomassa mostrados na tabela 1 , destaque deve ser dado à eficiência da leucena e do guandu, quando produziram 12,48 e 9,39 $\mathrm{t} \mathrm{ha}^{-1}$, correspondente as maiores quantidades, respectivamente, enquanto que a crotalária, com $1,97 \mathrm{tha}^{-1}$, a menor eficiência. Ainda nesta tabela, observa-se grande variação deste componente entre tratamentos podendo serem atribuídas a resistência e a sensibilidade das espécies ao déficit hídrico registrado na fase vegetativa, e das condições de degradação da área experimental. As produções de fitomassa de guandu, lab-lab e siratro foram superiores às encontradas por BRAGAGNOLO \& MIELNICZUK (1990) e por RIBEIRO (1999), e as de mucuna preta, feijão-de-porco e crotalária, superiores às encontradas por DE POLLI \& CHADA (1989) e RIBEIRO (1999). A eficiência destas espécies atribui-se à melhoria que proporcionaram ao solo pelo seu manejo, referenciadas pelos próprios autores acima citados.

O teor de nitrogênio total, para a maioria dos tratamentos, foi considerado relativamente baixo, provavelmente influenciado pelas condições de clima e solo do experimento, fato também constatado por Lima (1990). Destaque deve ser dado ao kudzu tropical que apresentou teores médios de nitrogênio total e proteína bruta superiores dos demais tratamentos.

Na comparação das médias de matéria orgânica e cinzas (Tabela 1), verificou-se o efeito inverso, como era de se esperar. Para a matéria orgânica, as médias do siratro e da leucena, foram inferior e superior, respectivamente, enquanto que para cinzas, em ambos os tratamentos, o efeito foi significativo e contrário. De acordo com SILVA (1990), os resultados relatados à cinzas do siratro, crotalária, feijão-de-porco, calopogônio e mucuna

Tabela 1 - Valores médios dos componentes de leguminosas. Centro de Ciências Agrárias, Universidade Federal da Paraíba, Areia-PB, 2000.

\begin{tabular}{|c|c|c|c|c|c|c|c|}
\hline \multirow{2}{*}{ Tratamentos } & \multicolumn{7}{|c|}{ Determinações } \\
\hline & MS & NT & PB & MO & $\mathrm{CZ}$ & FDN & FDA \\
\hline & $\mathrm{t} \mathrm{ha}^{-1}$ & \multicolumn{6}{|c|}{$\%$} \\
\hline Guandu & $9,39 b^{*}$ & $1,25 \mathrm{f}$ & $7,82 \mathrm{c}$ & $88,34 \mathrm{abc}$ & $11,66 \mathrm{efg}$ & $70,64 \mathrm{ab}$ & $52,54 \mathrm{abc}$ \\
\hline Guandu anão & 5,68 def & $1,24 \mathrm{f}$ & $8,07 \mathrm{c}$ & $89,60 \mathrm{abc}$ & $10,93 \mathrm{fg}$ & $67,52 \mathrm{bc}$ & $50,54 \mathrm{abc}$ \\
\hline Lab lab & $4,21 \mathrm{fg}$ & $1,21 \mathrm{f}$ & $7,57 \mathrm{c}$ & $86,03 \mathrm{abc}$ & $13,96 \mathrm{def}$ & $68,55 \mathrm{abc}$ & $52,89 \mathrm{ab}$ \\
\hline Mucuna preta & $7,68 \mathrm{bc}$ & $1,45 \mathrm{~cd}$ & $9,02 \mathrm{bc}$ & $84,83 a b c$ & 15,27 cde & $71,39 \mathrm{ab}$ & $55,46 \mathrm{a}$ \\
\hline Mucuna cinza & $6,52 \mathrm{cde}$ & $1,42 \mathrm{de}$ & $8,87 \mathrm{bc}$ & $83,81 \mathrm{abc}$ & $16,18 \mathrm{bcd}$ & $67,47 \mathrm{bc}$ & $55,42 \mathrm{a}$ \\
\hline Cunha & 6,76 cde & $1,61 \mathrm{~b}$ & $10,08 \mathrm{~b}$ & $88,50 \mathrm{abc}$ & 11,49 efg & $68,79 \mathrm{abc}$ & $52,00 \mathrm{abc}$ \\
\hline Calopogônio & $3,36 \mathrm{gh}$ & $1,58 \mathrm{bc}$ & $9,90 \mathrm{~b}$ & $82,03 \mathrm{abc}$ & $17,97 \mathrm{abc}$ & $65,22 \mathrm{bc}$ & $49,00 \mathrm{abc}$ \\
\hline Siratro & 5,38 ef & $1,41 \mathrm{de}$ & $8,82 \mathrm{bc}$ & $77,53 \mathrm{c}$ & $21,46 \mathrm{a}$ & $61,56 \mathrm{~cd}$ & $45,04 \mathrm{bc}$ \\
\hline Crotalária & $1,97 \mathrm{~h}$ & $1,26 \mathrm{f}$ & $7,90 \mathrm{c}$ & $80,58 \mathrm{bc}$ & $19,41 \mathrm{ab}$ & $67,16 \mathrm{bc}$ & $52,70 \mathrm{ab}$ \\
\hline Feijão-de-porco & $6,91 \mathrm{cde}$ & $1,41 \mathrm{de}$ & $8,51 \mathrm{bc}$ & $80,73 \mathrm{bc}$ & $19,26 a b$ & $66,84 \mathrm{bc}$ & $51,58 \mathrm{abc}$ \\
\hline Kudzu tropical & $7,58 \mathrm{bcd}$ & $1,89 \mathrm{a}$ & $11,81^{\mathrm{a}}$ & $92,08 \mathrm{ab}$ & $7,87 \mathrm{gh}$ & $57,98 \mathrm{~d}$ & $42,61 \quad \mathrm{c}$ \\
\hline Leucena & $12,48 \mathrm{a}$ & $1,29 \mathrm{ef}$ & $8,09 \mathrm{c}$ & $95,03 \mathrm{a}$ & $4,96 \mathrm{~h}$ & $75,59 \mathrm{a}$ & 56,66 a \\
\hline DMS & 1,94 & 0,14 & 1,68 & 13,90 & 3,96 & 8,01 & 9,98 \\
\hline $\mathrm{CV}(\%)$ & 10,06 & 3,46 & 6,41 & 5,46 & 9,41 & 4,00 & 6,54 \\
\hline
\end{tabular}

*Médias não seguidas pelas mesmas letra na coluna diferem entre si pelo teste de Tukey ao nível de $5 \%$ de probabilidade de erro.

Componentes: massa seca (MS), nitrogênio total (NT), proteína bruta (PB), matéria orgânica (MO), cinza (CZ), fibra em detergente neutro (FDN) e fibra em detergente ácido (FDA). 
cinza, sugerem certa eficiência na absorção de minerais.

Com relação à fibra em detergente neutro (FDN), as médias da leucena e do siratro foram, respectivamente, superior e inferior aos demais tratamentos, enquanto as médias de fibra em detergente ácido (FDA) da leucena, mucuna preta e cinza foram superiores e a do kudzu tropical, inferior aos demais tratamentos.

Nas condições de solo e clima do experimento, a leucena, o guandu, a mucuna preta, o kudzu tropical, o feijão-de-porco, a cunhã e a mucuna cinza produziram, em ordem decrescente, as maiores quantidades de fitomassa, enquanto o kudzu tropical mostrou-se mais eficiente para uso como adubação verde na região.

\section{REFERÊNCIAS BILBLIOGRÁFICAS}

A. O. A. C. ASSOCIATION OF OFFICIAL AGRICULTURAL CHEMISTS. Official methods of analysis. 14.ed. Washington DC., 1984. 1141p.
BRAGAGNOLO, N.; MIELNICZUK, J. Cobertura do solo por resíduos de oito seqüências de culturas e seu relacionamento com a temperatura e umidade do solo, germinação e crescimento inicial do milho. Revista Brasileira de Ciência do Solo, Campinas, v.14, p.91-98, 1990.

DE-POLLI, H.; CHADA, S. de S. Adubação verde incorporada ou em cobertura na produção de milho em solo de baixo potencial de produtividade. Revista Brasileira de Ciência do Solo, Campinas, v.13, p.287-293, 1989.

KIEHL, E.J. Fertilizantes orgânicos. Piracicaba : Ceres, 1985. 492p.

RIBEIRO, P.A. Utilização de leguminosas na produção de biomassa e como fonte de nutrientes em um Podzólico Vermelho-Amarelo no município de Alagoinha-PB. 1999. 57f. Dissertação (Mestrado em Manejo de Solo e Água) - Universidade Federal da Paraíba.

SILVA, D J. Análise de alimentos: métodos químicos e biológicos. 2.ed. Viçosa : UFV, 1990. 165p.

VAN SOEST, P.J. Development of a comprehensive system of feed analysis and its application to forages. J Anim Sci, v.26, n.1, p.119-128, 1967. 